\title{
Cobalt nanoparticles encapsulated in nitrogen-doped carbon for room-temperature selective hydrogenation of nitroarenes
}

\author{
Ruijie Gao a,b, Lun Pan a,b, Zhengwen Li a, Xiangwen Zhang a,b, Li Wang a,b, Ji-Jun Zou a,b,* \\ a Key Laboratory for Green Chemical Technology of the Ministry of Education, School of Chemical Engineering and Technology, Tianjin University, Tianjin \\ 300072, China \\ b Collaborative Innovative Center of Chemical Science and Engineering (Tianjin), Tianjin 300072, China
}

\section{A R T I C L E I N F}

\section{Article history:}

Received 29 November 2017

Accepted 22 December 2017

Published 5 April 2018

\section{Keywords:}

Cobalt nanoparticle

Nitrogen-doped carbon

Nitroarenes

Selective hydrogenation

Hydrogen activation

Heterogeneous catalysis

\begin{abstract}
A B S T R A C T
Here, we report cobalt nanoparticles encapsulated in nitrogen-doped carbon (Co@NC) that exhibit excellent catalytic activity and chemoselectivity for room-temperature hydrogenation of nitroarenes. Co@NC was synthesized by pyrolyzing a mixture of a cobalt salt, an inexpensive organic molecule, and carbon nitride. Using the Co@NC catalyst, a turnover frequency of $\sim 12.3 \mathrm{~h}^{-1}$ and selectivity for 4-aminophenol of $>99.9 \%$ were achieved for hydrogenation of 4-nitrophenol at room temperature and 10 bar $\mathrm{H}_{2}$ pressure. The excellent catalytic performance can be attributed to the cooperative effect of hydrogen activation by electron-deficient Co nanoparticles and energetically preferred adsorption of the nitro group of nitroarenes to electron-rich N-doped carbon. In addition, there is electron transfer from the Co nanoparticles to N-doped carbon, which further enhances the functionality of the metal center and carbon support. The catalyst also exhibits stable recycling performance and high activity for nitroaromatics with various substituents.
\end{abstract}

(C) 2018, Dalian Institute of Chemical Physics, Chinese Academy of Sciences. Published by Elsevier B.V. All rights reserved.

\section{Introduction}

Selective hydrogenation of nitroarenes is a promising approach to produce aromatic amines and aminocyclohexanes $[1,2]$. Aromatic amines are important bulk chemicals in many fields, including production of fine chemicals, commercial products, and polymers $[3,4]$. Along with the products of hydrogenation of the nitro groups, some byproducts are also produced, such as nitroso and azo compounds. For substituted nitroarenes with reducible groups (e.g., $-\mathrm{Cl},-\mathrm{C}=\mathrm{O}$, and $-\mathrm{CHO}$ groups), selective hydrogenation of the nitro group is a great challenge. Noble-metal-based catalysts have been used for the chemical transformation of nitrobenzene to aniline, and excellent selectivities and activities have been achieved under mild conditions [5-13]. However, noble-metal-free catalysts are preferred in industry because of their low cost and abundance. In this case, transition-metal- [14-22] and carbon-based [23-28] catalysts show potential for selective hydrogenation of nitrobenzene, but they suffer from low activity and require harsh reaction conditions. To achieve high activity and selectivity under mild conditions, both the $\mathrm{H}_{2}$ molecules and nitro groups must be effectively activated, which is difficult to achieve with a catalyst containing only a single type of active site.

For bifunctional catalysts composed of a carbon-based material loaded with a transition-metal-based catalyst, the support material can not only confine the metal atoms, but it can also modify the electronic environment of the metal nanoparti-

\footnotetext{
* Corresponding author. Tel/Fax: +86-22-27892340; E-mail: jj_zou@tju.edu.cn

This work was supported by the National Natural Science Foundation of China (U1462119) and the Tianjin Municipal Natural Science Foundation (16JCQNJC05200).

DOI: 10.1016/S1872-2067(17)62988-7 | http://www.sciencedirect.com/science/journal/18722067 | Chin. J. Catal., Vol. 39 , No. 4, April 2018
} 
cles (in a way similar to homogeneous catalysts with organic ligands), which increases the catalytic activity. Recently, earth-abundant metals (e.g., Co) have been used for hydrogenation of nitrobenzene $[14,20]$. Reduced cobalt can act as a hydrogen acceptor owing to the electron-deficient state of its surface, which promotes cleavage of $\mathrm{H}-\mathrm{H}$ bonds. However, it suffers from low chemoselectivity because of coadsorption of two or more nitroarenes. In this case, catalytic coupling of azo compounds can occur. Heteroatom-doped carbon with an adjustable electron structure and chemical stability can stabilize metal nanoparticles [29-33]. Doping $N$ atoms into the carbon matrix can cause charge delocalization [34-36] and a high positive charge density on the carbon atoms next to the doped $\mathrm{N}$ atoms, which are beneficial for adsorption of compounds containing a nitro group. $\mathrm{N}$-doped carbon has been used as a catalyst for hydrogenation of nitrobenzene because of the strong interaction between nitrobenzene and carbon catalysts [37], but its activity is still very low owing to its poor ability for $\mathrm{H}_{2}$ activation. Metal catalysts can also be activated by carbon-nitride-based materials [38-40], where the electron density of the metal centers changes because in-lattice $\mathrm{N}$ atoms act as electron-accepting groups. Therefore, using $\mathrm{N}$-doped carbon as a support for metal-based nanocatalysts is expected to enhance their catalytic activity.

Inspired by the above findings, we developed a synergetic catalyst composed of Co nanoparticles encapsulated in $\mathrm{N}$-doped carbon (Co@NC) for room-temperature selective hydrogenation of nitroarenes. The $\mathrm{N}$-doped carbon and cobalt center play roles in preferential adsorption of nitroarene and $\mathrm{H}_{2}$ activation, so their synergetic effect leads to excellent activity and selectivity. The Co@NC catalysts were synthesized by calcining a mixture of a cobalt salt, an inexpensive organic molecule, and carbon nitride. The optimized Co@NC-1 catalyst shows excellent activity and selectivity at room temperature, which cannot be achieved using bare N-doped carbon or pristine-carbon-supported Co nanoparticle catalysts.

\section{Experimental}

\subsection{Catalyst synthesis}

To fabricate carbon nitride $\left(\mathrm{g}-\mathrm{C}_{3} \mathrm{~N}_{4}\right)$, melamine was placed in a covered crucible, heated to $550{ }^{\circ} \mathrm{C}$ for $4 \mathrm{~h}$ under an inert environment, and then maintained at $550{ }^{\circ} \mathrm{C}$ for another $4 \mathrm{~h}$. The as-synthesized yellow solid was ground into a powder, which was used to produce $\mathrm{N}$-doped carbon. The homogeneous cobalt-containing precursor solution was prepared by dissolving cobalt nitrate hexahydrate (1.168 g) and triethylene diamine (1.92 g) in $40 \mathrm{~mL}$ of deionized water. g- $\mathrm{C}_{3} \mathrm{~N}_{4}(1.0,2.0$, or 4.0 g for Co@NC-0.5, Co@NC-1, or Co@NC-2, respectively) was added to the aqueous solution under magnetic stirring. Owing to the effect of the $\mathrm{Co}-\mathrm{N}$ bond, $\mathrm{Co}^{2+}$ ions can embed in the holes of carbon nitride and triethylene diamine molecules prevent excessive growth of Co particles during the following pyrolysis treatment. After the solvent was removed by vacuum freeze-drying, the solid powder was transferred to a covered crucible, heated to $900{ }^{\circ} \mathrm{C}$ at a rate of $2.5{ }^{\circ} \mathrm{C} / \mathrm{min}$ under a $\mathrm{N}_{2}$ atmosphere, and maintained at this temperature for $2 \mathrm{~h}$. The as-obtained black solid samples were used for characterization and the catalytic reactions. To further investigate the role of N-doped carbon, Co@C was prepared by the conventional impregnation method using commercial carbon (VX720R) as the support. Pure N-doped carbon was also synthesized by pyrolysis of $g-\mathrm{C}_{3} \mathrm{~N}_{4}$.

\subsection{Characterization}

Transmission electron microscopy (TEM) was performed with a Tecnai G2 F20 transmission electron microscope at 200 $\mathrm{kV}$. The crystal structures were determined by a RigaKu D/max-2500 X-ray diffractometer (XRD) equipped with a $\mathrm{Cu} K_{\alpha}$ irradiation source. Elemental analysis was performed with a Vario EL Cube equipped with a METTLER x86 instrument. The elemental composition and bonding information were obtained by X-ray photoelectron spectroscopy (XPS) at a pass energy of 187.85 eV (Physical Electronics PHI 1600 ESCA XPS system using a monochromated $\mathrm{Al} K_{\alpha} \mathrm{X}$-ray source) using the $\mathrm{C} 1 s$ peak at $284.6 \mathrm{eV}$ as the internal standard. The nitrogen adsorption-desorption isotherms were determined with a ASAP 2020 physisorption analyzer at $-196^{\circ} \mathrm{C}$, and the specific surface areas were calculated by the conventional Brunauer-EmmettTeller (BET) method. The pore size distribution in the mesopore range was determined by the Barrett-Joyner-Halenda method. Before performing the measurements, all the samples were outgassed under vacuum at $200{ }^{\circ} \mathrm{C}$ for $12 \mathrm{~h}$ until the pressure was less than $0.66 \mathrm{~Pa}$. The Fourier transform infrared spectroscopy (FTIR) spectra were recorded with a BioRad FTS 6000 spectrometer. Raman spectroscopy was performed with a Raman spectrometer (DXR Microscope) using a green semiconductor laser (532 $\mathrm{nm})$ as the excitation source.

\subsection{Catalytic hydrogenation of nitroarenes}

Hydrogenation was performed in a $50-\mathrm{mL}$ autoclave with a polytetrafluoroethylene lining using $0.5 \mathrm{mmol}$ of the nitroarene, $5 \mathrm{~mL}$ of the solvent, and $30 \mathrm{mg}$ of the catalyst. The autoclave was purged with $\mathrm{N}_{2}$ and $\mathrm{H}_{2}$ (15 bar) three times and then pressurized to 10 bar. After the reaction, the catalyst was separated by centrifugation, followed by analysis of the sample by gas chromatography (GC)-mass spectroscopy (MS) (Agilent 5975 equipped with a HP-5 capillary column) and GC (Agilent 7820 equipped with a flame ionization detector and AT-SE-54 capillary column).

\section{Results and discussion}

To enable large-scale production of Co@NC for possible use as a heterogeneous catalyst, we developed a freeze-drying method using cobalt nitrate as the metal salt and carbon nitride as the $\mathrm{N}$ precursor. The solid mixture was carbonized at $900{ }^{\circ} \mathrm{C}$ under an inert atmosphere (Fig. 1(a)). The X-ray diffraction (XRD) patterns indicate formation of metallic cobalt [41] (the peaks at about $44^{\circ}$ and $51^{\circ}$ are assigned to the (111) and (200) diffractions of Co nanoparticles) and graphitic carbon (the peak 

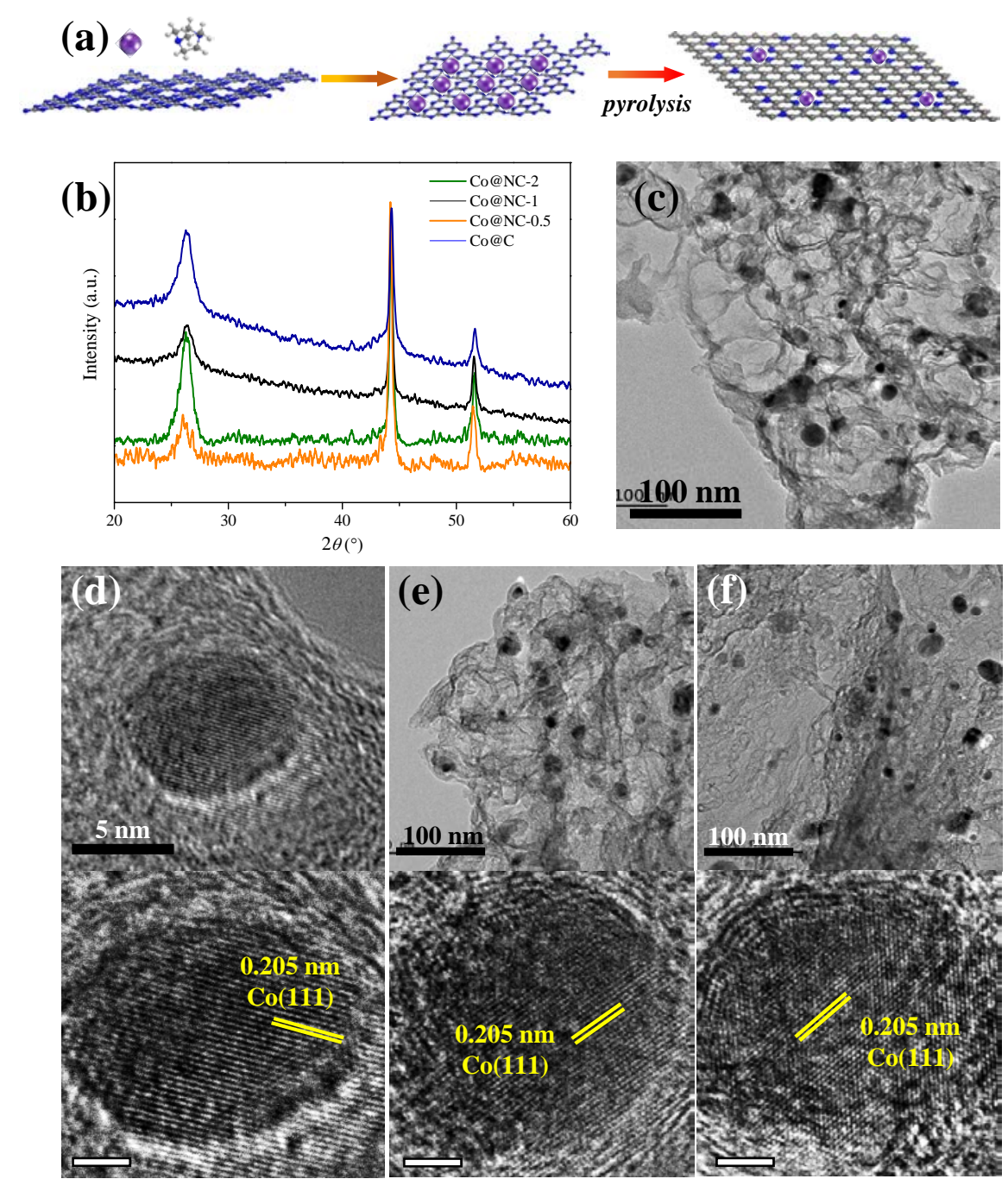

Fig. 1. (a) Proposed synthetic protocol for preparation of Co@NC catalysts from metal and organic precursors ( $\mathrm{Co}^{2+}$ cations and triethylene diamine) and bulk carbon nitride. Carbon atoms are gray, nitrogen atoms are blue, cobalt atoms are purple, and hydrogen atoms are white. (b) XRD patterns of the Co@NC and Co@C catalysts. (c) Typical TEM and (d) HRTEM images of Co@NC-1 (scale bar 2 nm). Typical TEM and HRTEM images of Co@NC-0.5 (e) and Co@NC-2 (scale bar 2 nm) (f).

at about $26^{\circ}$ ) [42,43] (Fig. 1(b)), and also exclude coexistence of detectable amounts of cobalt oxides, nitrides, and carbides. The carbon peak becomes more intensive with addition of graphitic carbon nitride. All of the TEM images (Fig. 1(c)-(f)) show that the Co nanoparticles in Co@NC have a similar average size of $\sim 10 \mathrm{~nm}$, indicating that the amount of carbon nitride does not influence the size of the Co nanoparticles. Furthermore, the high-resolution TEM (HRTEM) image of Co@NC shows a highly integrated nanostructure of layered carbon-coated Co nanoparticles (Fig. 1(d)). The lattice spacing of all of the catalysts is $0.205 \mathrm{~nm}$ (Fig. 1(d)-(f)), which is attributed to the (111) plane of metallic cobalt [41]. The carbon layers can act as a shell to protect the metallic Co nanoparticles from aggregation and oxidation during pyrolysis and the following reaction processes. The porosity of the synthesized Co@NC catalysts was evaluated by nitrogen adsorption-desorption (Fig. 2(a)). With increasing amount of carbon nitride, the BET surface area of the catalyst does not significant change (80.78, 81.46, and $86.31 \mathrm{~m}^{2} \mathrm{~g}^{-1}$ for Co@NC-0.5, Co@NC-1, and Co@NC-2, respectively). XPS and elemental analysis were performed to obtain further information about the chemical compositions of the catalysts (Fig. 2(b) and Table 1). The results indicate that the $\mathrm{N}$ concentration in the bulk is very close to that on the surface and the $\mathrm{N}$ concentration increases with increasing carbon nitride addition (1.75 and 3.62 at\% for Co@NC-0.5 and Co@NC-1, respectively). Further increasing the amount of carbon nitride powder does not significantly increase the nitrogen concentration (3.73 at $\%$ for Co@NC-2). The Raman spectra (Fig. 2(c)) show two distinct signals at 1350 and $1590 \mathrm{~cm}^{-1}$, which are assigned to defective/disordered $s p^{3}$ hybridized carbon (D band) and crystallized graphitic $s p^{2}$ carbon (G band), respectively. The ratio of the intensity of the $\mathrm{D}$ band to the intensity of the $\mathrm{G}$ band $I_{\mathrm{D}} / I_{\mathrm{G}}$ increases from 0.908 (Co@NC-0.5) to 1.0 (Co@NC-1) upon increasing the added amount of carbon nitride.

The Co@NC catalysts were applied to hydrogenation of 

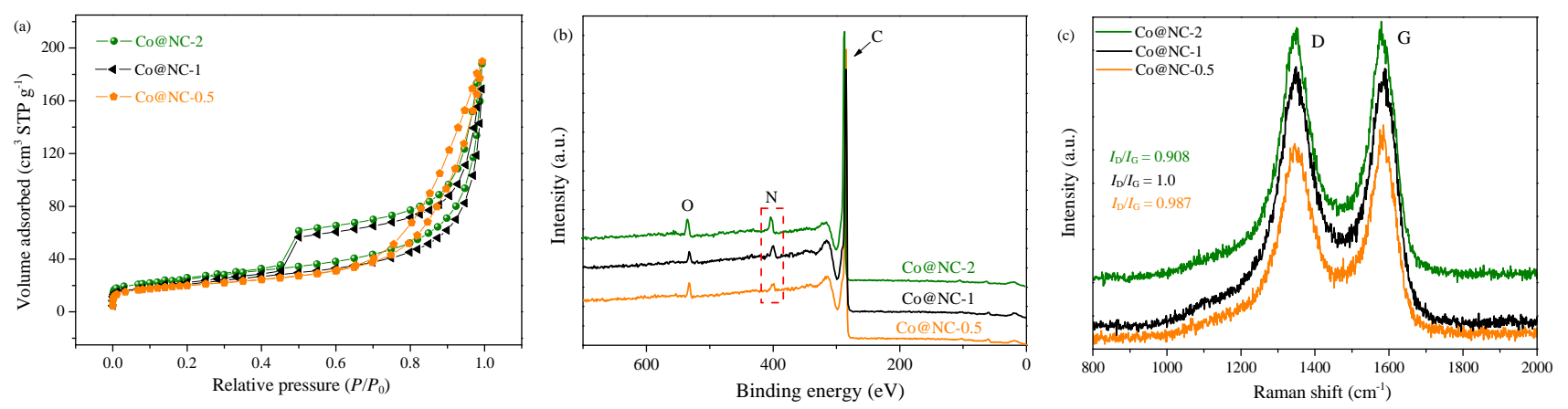

Fig. 2. $\mathrm{N}_{2}$ adsorption isotherms (a), XPS spectra (b), and Raman spectra (c) of the Co@NC catalysts.

4-nitrophenol to test their catalytic activity. The hydrogenation reactions were performed at room temperature under a $\mathrm{H}_{2}$ pressure of 10 bar. When $\mathrm{N}$-doped carbon was used as the catalyst, no catalytic hydrogenation product was obtained even after reacting for $12 \mathrm{~h}$, demonstrating the inert nature of $\mathrm{N}$-doped carbon for hydrogenation of 4-nitrophenol under mild reaction conditions, which is because of its poor ability for hydrogen activation. The catalytic behavior of the Co@NC catalysts is shown in Fig. 3(a), where conversion of 4-nitrophenol is plotted as a function of the reaction time. Co@NC-0.5 can initiate hydrogenation of 4-nitrophenol, with total conversion of 4-nitrophenol in $5 \mathrm{~h}$ but with poor chemoselectivity for 4-aminophenol (78.1\%). Co@NC-1 exhibits the best performance among the catalysts tested, giving complete conversion of 4-nitrophenol in $3 \mathrm{~h}$ and a turnover frequency (TOF) based on the amount of Co at 30 min of $12.3 \mathrm{~h}^{-1}$. More importantly, the chemoselectivity for 4 -aminophenol is $>99.9 \%$ and the amounts of the byproducts are below the detection limitation of GC-MS and GC (Fig. 3(b) and (c)). Co@NC-2 does not perform better than Co@NC-1 because a further increase in the amount of $\mathrm{g}-\mathrm{C}_{3} \mathrm{~N}_{4}$ does not further increase the $\mathrm{N}$ doping concentration. To understand the important role of N-doped carbon, commercial carbon-supported Co nanoparticles (Co@C) were synthesized and applied for hydrogenation of 4-nitrophenol under the same conditions. After $3 \mathrm{~h}$, conversion of 4-nitrophenol was only $5.6 \%$ and it did not significantly increase even for a prolonged reaction period. Furthermore, large amounts of byproducts (i.e., azoxy compounds) were produced and the selectivity for 4-aminophenol was only $67.1 \%$.

Different solvents (water, tetrahydrofuran (THF), and cyclohexane) were tested using Co@NC-1 as the catalyst (Table 2). The activity improves with increasing polarity of the solvent. The polarity of the solvent has a significant effect on many

Table 1

Compositions of the Co@NC catalysts determined by XPS and elemental analysis.

\begin{tabular}{|c|c|c|c|c|}
\hline \multirow{2}{*}{ Catalyst } & Co (at $\%)$ & C (at\%) & $\mathrm{N}$ (at\%) & $\mathrm{O}$ (at $\%)$ \\
\hline & Surface ${ }^{a}$ & Surface ${ }^{\mathrm{a}} / \mathrm{bulk}^{\mathrm{b}}$ & Surface $\mathrm{a} / \mathrm{bulk}^{\mathrm{b}}$ & Surface $\mathrm{a} / \mathrm{bulk}^{\mathrm{b}}$ \\
\hline Co@NC-0.5 & 0.76 & $94.15 / 95.28$ & $1.76 / 1.75$ & $3.33 / 2.97$ \\
\hline Co@NC-1 & 0.75 & $93.46 / 95.10$ & $3.82 / 3.62$ & $1.97 / 1.28$ \\
\hline Co@NC-2 & 0.73 & $92.17 / 93.41$ & $3.68 / 3.73$ & $3.42 / 2.86$ \\
\hline
\end{tabular}

a Calculated from XPS measurements.

${ }^{\mathrm{b}}$ Calculated from elemental analysis. reactions [41], especially hydrogenation of nitrobenzene $[14,42]$. One important factor is the interaction between the nitro group and the polar solvent by $\mathrm{OH} \cdots \mathrm{N}$ and $\mathrm{OH} \cdots \mathrm{O}$ hydrogen bonds, which accelerates polarization of $\mathrm{N}=\mathrm{O}$ and $\mathrm{N}-\mathrm{O}$ and weakens the bond strength $[46,47]$. Another important factor is the easy of adsorption and dissociation of hydrogen on the catalyst surface in the polar solvent [48]. As shown in Table 2, higher reaction temperature and $\mathrm{H}_{2}$ pressure accelerate the reaction.

The control experiments indicate that Co@NC-1 has very high catalytic activity and excellent chemoselectivity for hydrogenation of 4-nitrophenol. To determine how N-doped carbon and Co nanoparticles synergistically catalyze selective hydrogenation of 4-nitrophenol, further characterizations of Co@NC-1 were performed. The similar morphologies of the Co@NC catalysts mean that it is not the cobalt content, particle size, or nanostructure of the Co nanoparticles that affects the catalytic activity. The surface area can also be excluded because Co@NC-1, Co@NC-0.5, and Co@NC-2 have similar surface areas, as shown in Fig. 2(a). As shown in the $\mathrm{N}$ 1s spectra (Fig. 4(a) and (b)), the doped $\mathrm{N}$ atoms are mainly graphitic and pyridinic $\mathrm{N}$ [30] (the peaks centered at about 401.5 and $399.0 \mathrm{eV}$, respectively). The shifts of the typical Co $2 p$ XPS peaks to higher energy and N $1 s$ XPS peaks to lower energy indicate a decrease in the electron density of the Co nanoparticles in Co@NC-1 compared with Co@NC-0.5, which confirms electron transfer at the interface of Co and N-doped carbon (Fig. 4(c)).

Theoretical investigation suggests that introduction of dopants into the carbon framework can make the electronic structure negative [34-36]. The nitro group, which is a strong electron-withdrawing group, will have a strong interaction with the electron-rich sites. Consequently, N-doped carbon has been used for catalytic hydrogenation of nitrobenzene [37]. For Co@NC-1, the relatively high N doping concentration results in electron redistribution at the interface of cobalt and $\mathrm{N}$-doped carbon, which enriches the positive charges on the metallic Co nanoparticle side and the negative charges on the $\mathrm{N}$-doped carbon side, as indicated by the XPS results (Fig. 4). Although both carbon with a high concentration of $\mathrm{N}$ atoms and metallic Co can act as adsorption sites for nitro groups, adsorption to electron-rich $\mathrm{N}$-doped carbon is preferred. In addition, the metallic phase provides active sites for $\mathrm{H}_{2}$ activation and promotes cleavage of $\mathrm{H}-\mathrm{H}$ bonds owing to its good electrophilicity. 

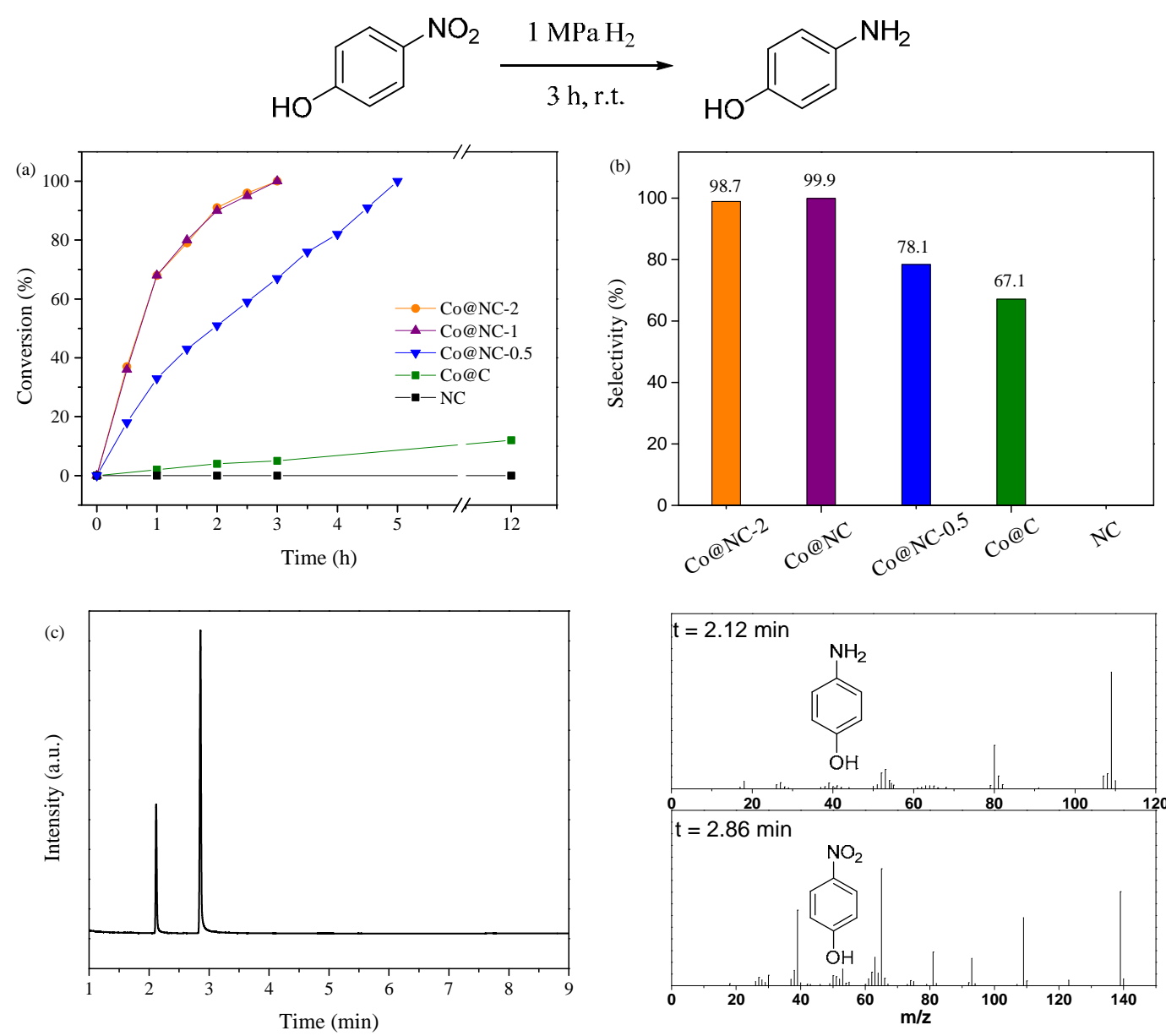

Fig. 3. Catalytic activity and chemoselectivity of various catalysts for hydrogenation of 4-nitrophenol. (a) Conversion of 4-nitrophenol with time. (b) Chemoselectivity for 4-aminophenol using various catalysts (reaction conditions: $0.5 \mathrm{mmol} 4$-nitrophenol, $30 \mathrm{mg}$ catalyst, $5 \mathrm{~mL}$ ethanol, room temperature, and 10 bar $\mathrm{H}_{2}$ ). (c) GC spectrum of the reaction product mixture after 1 h hydrogenation of 4-nitrophenol catalyzed by Co@NC-1 and the corresponding mass spectra.

Table 2

Effect of the reaction conditions on hydrogenation of 4-nitrophenol.

\begin{tabular}{|c|c|c|c|c|c|c|}
\hline Entry & Solvent & Time (h) & Temperature $\left({ }^{\circ} \mathrm{C}\right)$ & Pressure (bar) & Conversion (\%) & Selectivity (\%) \\
\hline$\overline{1}$ & Ethanol & 1 & 25 & 10 & 68.3 & $>99.0$ \\
\hline 2 & THF & 1 & 25 & 10 & 44.5 & $>99.0$ \\
\hline 3 & $\mathrm{H}_{2} \mathrm{O}$ & 1 & 25 & 10 & 88.1 & 95.7 \\
\hline 4 & Cyclohexane & 1 & 25 & 10 & 10.1 & $>99.0$ \\
\hline 5 & Ethanol & 1 & 40 & 10 & 84.2 & $>99.0$ \\
\hline 6 & Ethanol & 1 & 60 & 10 & 100.0 & $>99.0$ \\
\hline 7 & Ethanol & 1 & 25 & 5 & 23.5 & $>99.0$ \\
\hline 8 & Ethanol & 1 & 25 & 20 & 77.6 & $>99.0$ \\
\hline 9 & Ethanol & 1 & 25 & 30 & 91.2 & $>99.0$ \\
\hline 10 & Ethanol & 3 & 25 & 10 & 100.0 & $>99.0$ \\
\hline
\end{tabular}

Reaction conditions: 30 mg Co@NC-1, 0.5 mmol 4-nitrophenol, and 5 mL solvent.

Therefore, for Co@NC-1, the electron-transfer effect accelerates $\mathrm{H}_{2}$ activation over the Co nanoparticles and deprotonation of the $\mathrm{H}$-metal intermediates, which generates catalytically active sites to promote the whole reaction process. Here, we presume that 4-nitrophenol adsorbs to $\mathrm{N}$-doped carbon and the ab- sorbed nitro groups are then reduced by the surface hydrogen species, which is described as the synergistic effect of Co nanoparticles and N-doped carbon.

To better understand the excellent selectivity of Co@NC-1, the adsorption mode of 4-nitrophenol on different catalyst sur- 

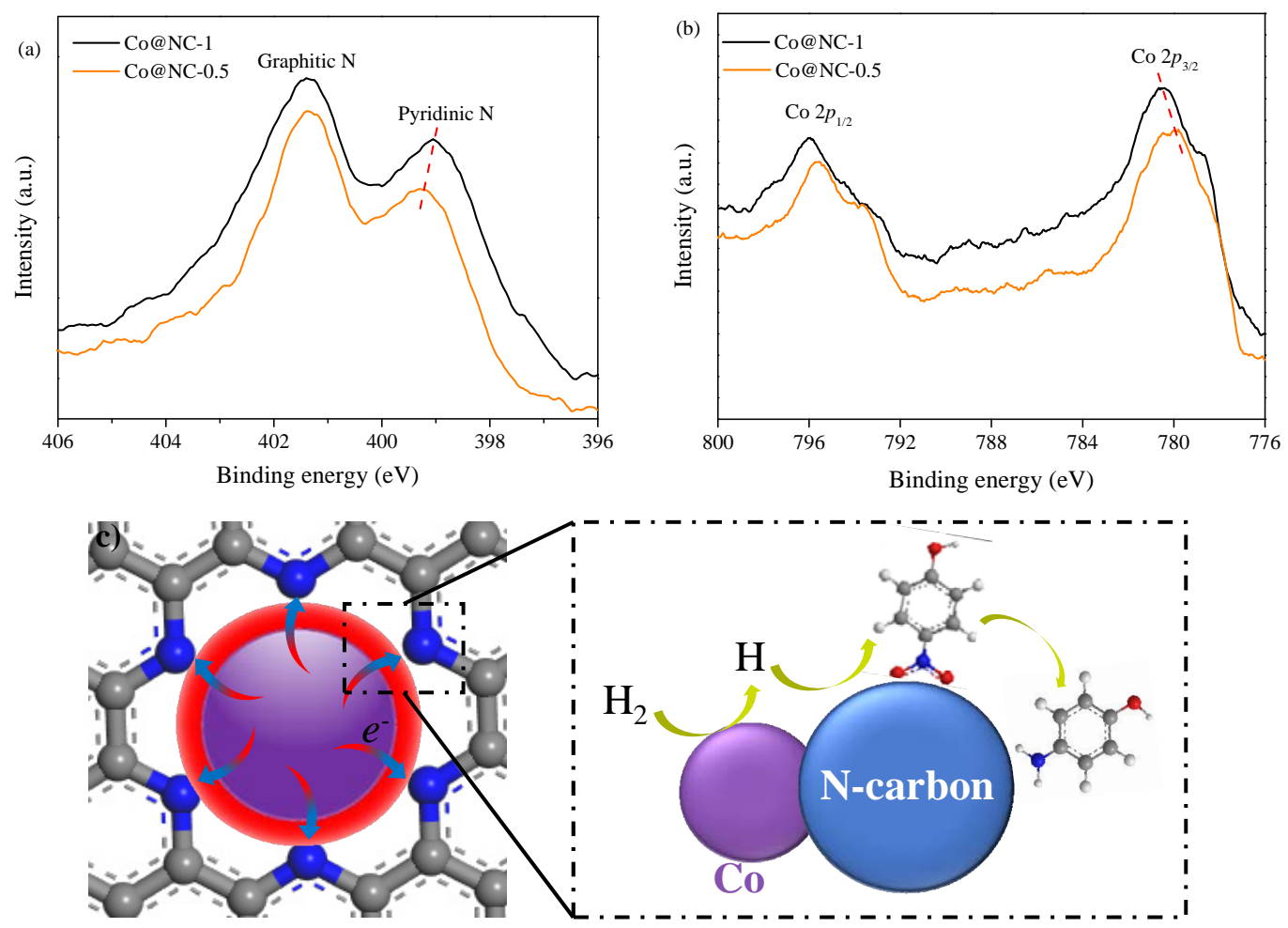

Fig. 4. N $1 s$ (a) and Co $2 p$ (b) XPS spectra of Co@NC-1. (c) Schematic illustration of the electron-transfer effect at the interface.
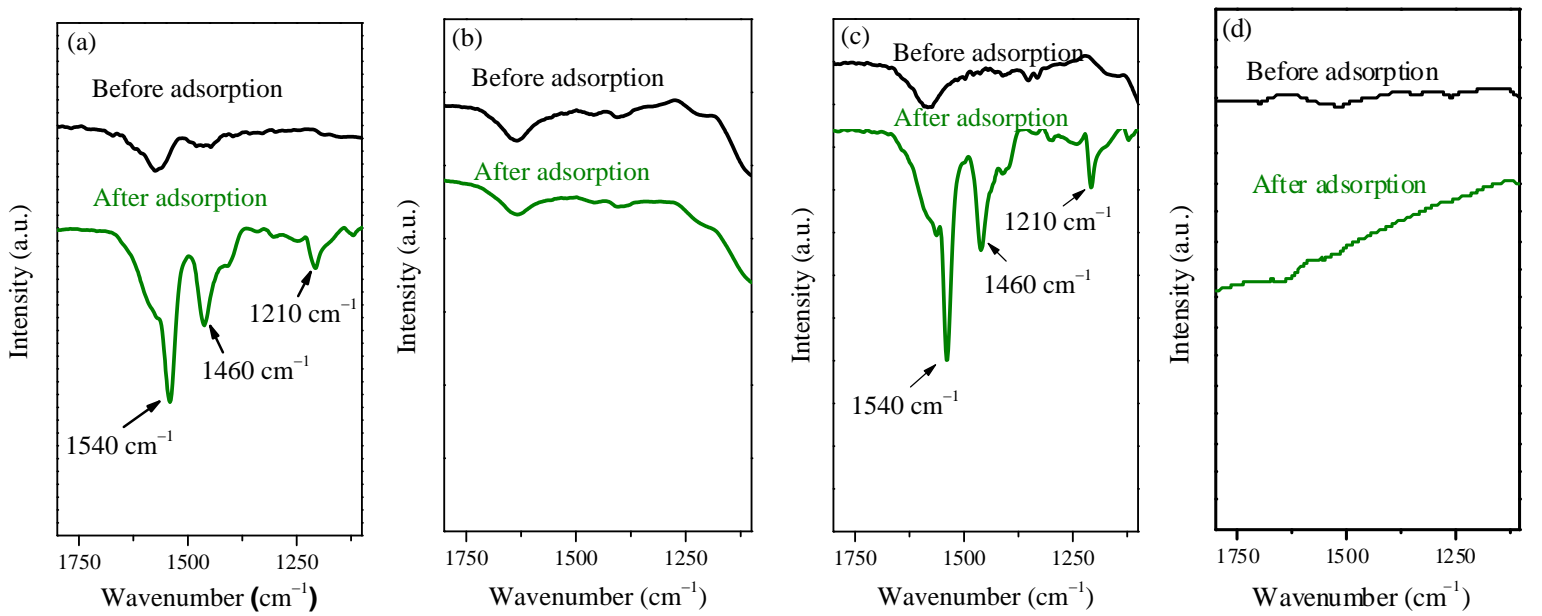

Fig. 5. FTIR spectra of N-doped carbon (a), the carbon support (b), Co@NC-1 (c), and Co@C (d) before and after adsorption of 4-nitrophenol.

faces was investigated by FTIR spectroscopy (Fig. 5). For $\mathrm{N}$-doped carbon, there are three characteristic peaks at 1210 , 1460 and $1540 \mathrm{~cm}^{-1}$ after adsorption of 4-nitrophenol, which are assigned to the stretching vibration of $\mathrm{C}-\mathrm{OH}$, framework vibration of benzene, and asymmetrical stretching of $-\mathrm{NO}_{2}$, respectively. In contrast, there are no characteristic peaks for the carbon support before and after adsorption. This confirms that 4-nitrophenol adsorbs on $\mathrm{N}$-doped carbon but not on pure carbon, which is because the pure carbon support is nearly inert for adsorption of both nitro and hydroxyl groups. However, Co@NC-1 shows similar signals to N-doped carbon, indicating that 4-nitrophenol molecules preferentially adsorb on
N-doped carbon.

The catalytic stability is also a very important criterion to evaluate the potential of a catalyst. Co-based catalysts can be easily recycled using an external magnetic field and reused up to ten times. As shown in Fig. 6(a), both the conversion of 4-nitrophenol and selectivity for 4-aminophenol are unchanged for ten cycles. The unchanged structural features further demonstrate the excellent catalytic stability of Co@NC-1 (Fig. 6(b)).

We also investigated hydrogenation of eight other substituted nitroarenes using the Co@NC-1 catalyst. The corresponding anilines were obtained in excellent yields with high 

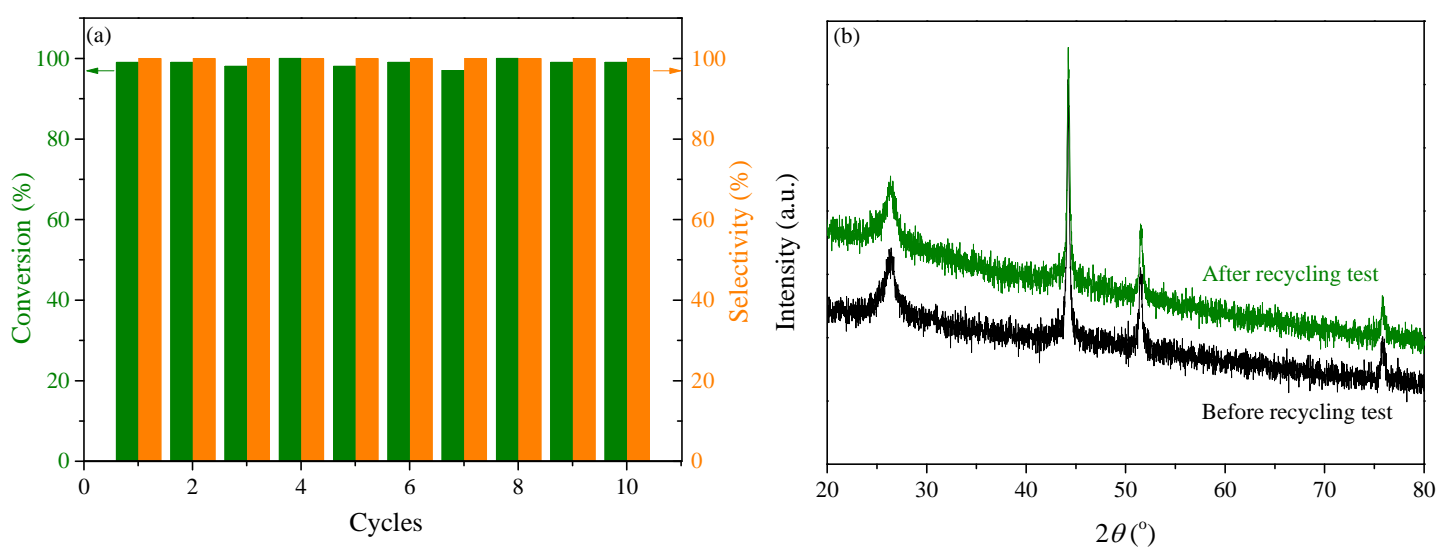

Fig. 6. (a) Catalytic stability and selectivity of Co@NC-1 after 3 h reaction time (reaction conditions: 0.5 mmol 4-nitrophenol, 30 mg catalyst, 5 mL ethanol, room temperature, and 10 bar $\mathrm{H}_{2}$ ). (b) XRD patterns of fresh and used Co@NC-1 after the recycling test.

selectivities (Table 3). Co@NC-1 selectively hydrogenates the nitro group while other functional groups, such as - $\mathrm{CHO}$, $-\mathrm{COOH}$, and $-\mathrm{C} \equiv \mathrm{C}$, are unaffected. For different substituted nitroarenes, different times are required to achieve full conversion. 4-Nitrostyrene takes $0.5 \mathrm{~h}$ more than 4-nitrophenol because the $\pi-\pi$ conjugative effect of the $-\mathrm{C}=\mathrm{C}$ group and benzene ring makes a relatively difficult for nitrostyrene to adsorb to the catalyst. For 3-nitrophenol, the nitro group is difficult to polarize because of the electron-donating effect of the $-\mathrm{OH}$ group at the meta position, which leads to a longer reaction time. In conclusion, this catalyst shows high activity and selectivity for hydrogenation of challenging substrates, suggesting

Table 3

Co@NC-1 catalyzed hydrogenation of substituted nitroarenes.

Entry Substrate

Reaction conditions: $0.5 \mathrm{mmol}$ substrate, $30 \mathrm{mg}$ Co@CN-1, $5 \mathrm{~mL}$ ethanol, room temperature, and 10 bar $\mathrm{H}_{2}$. that Co@NC-1 is a versatile catalyst for selective hydrogenation of substituted nitroarenes.

\section{Conclusions}

We have designed a heterogeneous synergetic catalyst for highly active and selective room-temperature hydrogenation of nitroarenes. The excellent catalytic performance can be attributed to the synergistic effect of $\mathrm{N}$-doped carbon for preferential adsorption of the nitro group and Co nanoparticles for activation of $\mathrm{H}_{2}$. Electron transfer from the Co nanoparticles to the $\mathrm{N}$-doped carbon atoms at the interface results in electron-rich N-doped carbon and electron-deficient Co nanoparticles, which further enhances the activity of $\mathrm{N}$-doped carbon for nitro group adsorption and $\mathrm{Co}$ for $\mathrm{H}_{2}$ activation. The optimized catalyst (Co@NC-1) exhibits excellent catalytic performance with a TOF of $12.3 \mathrm{~h}^{-1}$ and selectivity for aminophenol of $>99.9 \%$ at room temperature. This catalyst also exhibits high activity for hydrogenation of nitroarenes with various substituents.

\section{References}

[1] Y. G. Su, J. Y. Lang, L. P. Li, K. Guan, C. F. Du, L. M. Peng, D. Han, X. J. Wang, J. Am. Chem. Soc., 2013, 135, 11433-11436.

[2] D. Gärtner, A. Welther, B. R. Rad, R. Wolf, A. J. Wangelin, Angew. Chem. Int. Ed., 2014, 53, 3722-3726.

[3] T. E. Müller, K. C. Hultzsch, M. Yus, F. Foubelo, M. Tada, Chem. Rev., 2008, 108, 3795-3892.

[4] J. F. Hartwig, Nature, 2008, 455, 314-322.

[5] F. Cárdenas-Lizana, S. Gómez-Quero, A. Hugon, L. Delannoy, C. Louis, M. A. Keane, J. Catal., 2009, 262, 235-243.

[6] C. Kartusch, M. Makosch, J. Sá, K. Hungerbuehler, J. A. van Bokhoven, ChemCatChem, 2012, 4, 236-242.

[7] H. S. Wei, X. Y. Liu, A. Q. Wang, L. L. Zhang, B. T. Qiao, X. T. Yang, Y. Q. Huang, S. Miao, J. Y. Liu, T. Zhang, Nat. Commun., 2014, 5, 5634.

[8] S. Zhang, C. R. Chang, Z. Q. Huang, J. Li, Z. M. Wu, Y. Y. Ma, Z. Y. Zhang, Y. Wang, Y. Q. Qu, J. Am. Chem. Soc., 2016, 138, 2629-2637.

[9] G. X. Chen, C. F. Xu, X. Q. Huang, J. Y. Ye, L. Gu, G. Li, Z. C. Tang, B. H. Wu, H. Y. Yang, Z. P. Zhao, Z. Zhou, G. Fu, N. F. Zheng, Nat. Mater,, 2016, 15, 546-569. 


\section{Graphical Abstract}

Chin. J. Catal., 2018, 39: 664-672 doi: 10.1016/S1872-2067(17)62988-7

Cobalt nanoparticles encapsulated in nitrogen-doped carbon for room-temperature selective hydrogenation of nitroarenes

Ruijie Gao, Lun Pan, Zhengwen Li, Xiangwen Zhang, Li Wang, Ji-Jun Zou *

Tianjin University; Collaborative Innovative Center of Chemical Science and Engineering (Tianjin)

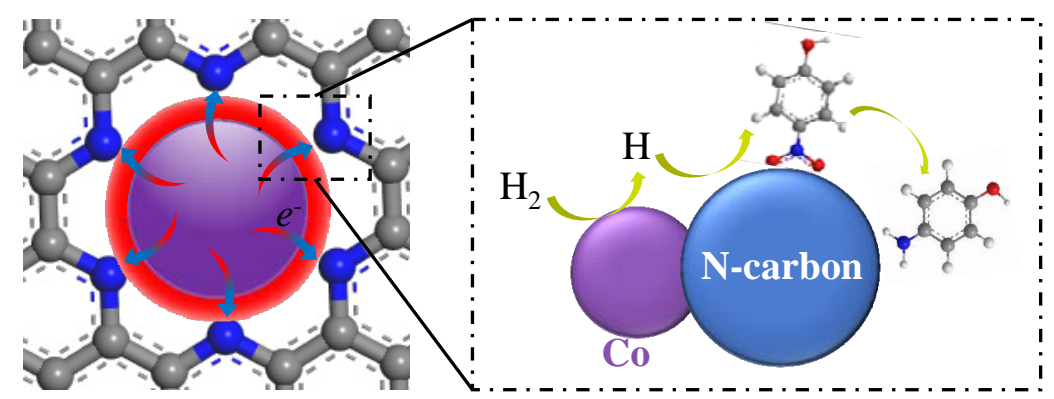

Cobalt nanoparticles encapsulated in N-doped carbon act as an efficient catalyst for room-temperature hydrogenation of nitroarenes owing to the synergetic effect of $\mathrm{H}_{2}$ activation on the Co nanoparticles and nitro group adsorption on $\mathrm{N}$-doped carbon.

[10] C. W. A. Chan, A. H. Mahadi, M. M. J. Li, E. C. Corbos, C. Tang, G. Jones, W. C. H. Kuo, J. Cookson, C. M. Brown, P. T. Bishop, S. C. E. Tsang, Nat. Commun., 2014, 5, 5787.

[11] A. S. Crampton, M. D. Rötzer, C. J. Ridge, F. F. Schweinberger, U. Heiz, B. Yoon, U. Landman, Nat. Commun., 2016, 7, 10389.

[12] G. Kennedy, G. Melaet, H. L. Han, W. T. Ralston, G. A. Somorjai, ACS Catal., 2016, 6, 7140-7147.

[13] S. Iqbal, S. A. Kondrat, D. R. Jones, D. Schoenmakers, J. K. Edwards, L. Lu, B. R. Yeo, P. P. Wells, E. K. Gibson, D. J. Morgan, C. J. Kiely, G. J. Hutchings, ACS Catal., 2015, 5, 5047-5059.

[14] F. A. Westerhaus, R. V. Jagadeesh, G. P. Wienhöfer, M. M. Pohl, J. Radnik, A. E. Surkus, J. Rabeah, K. Junge, H. Junge, M. Nielsen, A. Brückner, M. Beller, Nat. Chem., 2013, 5, 537-543.

[15] R. V. Jagadeesh, A. E. Surkus, H. Junge, M. M. Pohl, J. Radnik, J. Rabeah, H. Huan, V. Schünemann, A. Brückner, M. Beller, Science, 2013, 342, 1073-1076.

[16] J. J Song, Z. F. Huang, L. Pan, J. J. Zou, X. W. Zhang, L. Wang, ACS Catal., 2015, 5, 6594-6599.

[17] H. L. Niu, J. H. Lu, J. J. Song, L. Pan, X. W. Zhang, L. Wang, J. J. Zou, Ind. Eng. Chem. Res., 2016, 55, 8527-8533.

[18] J. H. Lu, J. J. Song, H. L. Niu, L. Pan, X. W. Zhang, L. Wang, J. J. Zou, Appl. Surf. Sci., 2016, 371, 61-66.

[19] Y. C. Zhang, L. Pan, J. H. Lu, J. J. Song, Z. Li, X. W. Zhang, L. Wang, J. J. Zou, Appl. Surf. Sci., 2017, 401, 241-247.

[20] Z. Z. Wei, J. Wang, S. J. Mao, D. F. Su, H. Y. Jin, Y. H. Wang, F. Xu, H. R. Li, Y. Wang, ACS Catal., 2015, 5, 4783-4789.

[21] H. Fan, X. Huang, L. Shang, Y. T. Cao, Y. F. Zhao, L. Z. Wu, C. H. Tung, Y. D. Yin, T. R. Zhang, Angew. Chem. Int. Ed., 2016, 55, 2167-2170.

[22] L. Shang, Y. H. Liang, M. Z. Li, G. I. N. Waterhouse, P. Tang, D. Ma, L. Z. Wu, C. H. Tung, T. R. Zhang, Adv. Func. Mater., 2017, 27, 1606215 .

[23] Y. M. Lin, S. C. Wu, W. Shi, B. S. Zhang, J. Wang, Y. A. Kin, M. Endo, D. S. Su, Chem. Commun., 2015, 51, 13086-13089.

[24] S. C. Wu, G. D. Wen, J. Wang, J. F. Rong, B. N. Zong, R. Schlögl, D. S. Su, Catal. Sci. Technol., 2014, 4, 4183-4187.

[25] Y. J. Gao, D, Ma, C. L. Wang, J. Guan, X. H. Bao, Chem. Commun., 2011, 47, 2432-2434.
[26] L. P. Zhang, J. B. Niu, L. M. Dai, Z. H. Xia, Langmuir, 2012, 28, 7542-7550.

[27] M. M. Trandafir, M. Florea, F. Neatu, A. Primo, V. I. Parvulescu, H. García, ChemSusChem, 2016, 9, 1565-1569.

[28] R. J. Gao, L. Pan, J. H. Lu, J. S. Xu, X. W. Zhang, L. Wang, J. J. Zou, ChemCatChem, 2017, 9, 4287-4294.

[29] B. V. Jagadeesh, H. Junge, M. M. Pohl, J. Radnik, A. Brückner, M. Beller, J. Am. Chem. Soc., 2013, 135, 10776-10782.

[30] H. Su, K. X. Zhang, B. Zhang, H. H. Wang, Q. Y. Yu, X. H. Li, M. Antoniett, J. S. Chen, J. Am. Chem. Soc., 2017, 139, 811-818.

[31] Y. J. Gao, D. Ma, G. Hu, P. Zhai, X. H. Bao, B. Zhu, B. S. Zhang, D. S. Su, Angew. Chem. Int. Ed., 2011, 50, 10236-10240.

[32] R. Liu, S. M. Mahurin, C. Li, R. R. Unocic, J. C. Idrobo, H. J. Gao, S. J. Pennycook, S. Dai, Angew. Chem. Int. Ed., 2011, 50, 6799-6802.

[33] X. F. Yu, L. B. Mao, J. Ge, Z. L. Yu, J. W. Liu, S. H. Yu, Sci. Bull., 2016, $61,700-705$

[34] M. Latorre-Sánchez, A. Primo, H. García, Angew. Chem. Int. Ed., 2013, 52, 11813-11816.

[35] C. Tang, H. F. Wang, X. Chen, B. Q. Li, T. Z. Hou, B. S. Zhang, Q. Zhang, M. M. Titirici, F. Wei, Adv. Mater, 2016, 28, 6845-6851.

[36] Y. J. Gao, G. Hu, J. Zhong, Z. J. Shi, Y. S. Zhu, D. S. Su, J. G. Wang, X. H. Bao, D. Ma, Angew. Chem. Int. Ed., 2013, 52, 2109-2113.

[37] X. K. Kong, Z. Y. Sun, M. Chen, C. L. Chen, Q. W. Chen, Energy Environ. Sci., 2013, 6, 3260-3266.

[38] Y. Y. Cai, X. H. Li, Y. N. Zhang, X. Wei, K. X. Wang, J. S. Chen, Angew. Chem. Int. Ed., 2013, 52, 11822-11825.

[39] L. H. Gong, Y. Y. Cai, X. H. Li, Y. N. Zhang, J. Su, J. S. Chen, Green Chem., 2014, 16, 3736-3751.

[40] X. H. Li, M. Antonietti, Chem. Soc. Rev., 2013, 42, 6593-6604.

[41] Y. Z. Chen, C. M. Wang, Z. Y. Wu, Y. J. Xiong, Q. Xu, S. H. Yu, H. L. Jiang, Adv. Mater., 2015, 27, 5010-5016.

[42] G. Kennedy, L. R. Baker, G. A. Sormorjai, Angew. Chem. Int. Ed., 2014, 53, 3405-3408.

[43] H. J. Yu, L. Shang, T. Bian, R. Shi, G. I. N. Waterhouse, Y. F. Zhao, C. Zhou, L. Z. Wu, C. H. Tung, T. R. Zhang, Adv. Mater., 2016, 28, 5080-5086.

[44] R. N. Butler, A. G. Coyne, Chem. Rev., 2010, 110, 6302-6337. 
[45] S. Zhang, C. R. Chang, Z. Q. Huang, J. Li, Z. M. Wu, Y. Y. Ma, Z. Y. Zhang, Y. Wang, Y. Q. Qu, J. Am. Soc. Chem., 2016, 138, 2629-2637.

[46] P. Maity, S. Basu, S. Bhaduri, G. K. Lahiri, Adv. Synth. Catal., 2007, 349, 1955-1962.

[47] X. C. Meng, H. Y. Cheng, S. Fujita, Y. C. Yu, F. Y. Zhao, M. Arai, Green
Chem., 2011, 13, 570-572.

[48] E. A. Gelder, S. D. Jackson, C. M. Lok, Catal. Lett., 2002, 84, 205-208.

[49] Z. Z. Wei, J. Wang, S. J. Mao, D. F. Su, H. Y. Jin, Y. H. Wang, F. Xu, H. R. Li, Y. Wang, ACS Catal., 2015, 5, 4783-4789.

\title{
氮掺杂碳包覆纳米钴颗粒用于硝基芳烃室温选择性加氢
}

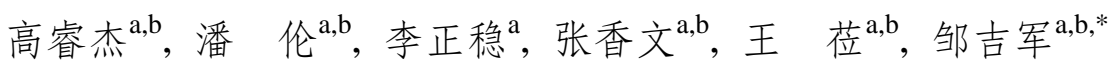 \\ ${ }^{\mathrm{a}}$ 天津大学化工学院, 绿色合成与转化教育部重点实验室, 天津300372 \\ ${ }^{\mathrm{b}}$ 天津化学化工协同创新中心, 天津 300372
}

\begin{abstract}
摘要: 通过硝基芳烃选择性加氢能高效地制备芳香胺和环胺, 其中芳香胺作为重要的化工中间体应用于多个领域(精细化 工、商业产品和聚合物). 在加氢反应过程中, 硝基的还原伴随着生成一些副产物(如亚硝基和偶氮化合物). 同时对于含还 原性基团的取代硝基苯, 硝基的选择还原也面临着很大的挑战. 金属钴是常用的硝基加氢催化剂活性成分, 但是由于对反 应底物的过度吸附, 导致其选择性不高. 早期研究发现, 氮掺杂碳催化剂能有效吸附硝基基团, 从而在硝基苯加氢中表现 出一定活性, 但对分子氢的活化不足. 因此, 氮掺杂碳作为吸附材料与钴构建复合催化剂, 能够发挥吸附和活化氢的协同 作用, 从而高效催化硝基苯加氢.

基于此, 本课题组发展了一种制备方法, 可将钴颗粒尺寸限制在 $10 \mathrm{~nm}$ 左右, 且包覆在氮掺杂碳中, 并应用于对硝基苯 酚的室温选择性加氢反应中, 发现相较于碳负载钴和氮掺杂碳催化剂, 所制催化剂在室温下表现出了很好的活性和选择 性. 在此基础上, 本文采用元素分析、X射线光电子能谱(XPS)和拉曼光谱(Raman)等手段对催化剂形貌和结构进行了研究.

表征结果表明, 保持钴前驱体的量不变, 随着氮化碳加入量的增加, 催化剂中氮掺杂浓度提高; 当氮化碳/钴 $>1$ 时, 氮掺 杂浓度不变. 红外结果表明, 与普通碳载体相比, 氮掺杂碳对硝基苯有很强的吸附作用, 而氮掺杂碳包覆的钴催化剂也表 现出同样的结果. 通过调节氮的掺杂浓度, 一方面可以修饰碳载体的电子结构, 增加表面缺陷的浓度, 提高与反应底物的 相互作用; 另一方面可以促进电子由钴颗粒转移至与之相连的氮原子上, 因此进一步促进钴颗粒对分子氢的活化作用. 该 复合结构的催化剂实现了底物吸附和氢活化的协同作用, 氮掺杂碳将反应底物吸附在表面, 钴颗粒活化氢, 随后解离的氢 原子与表面吸附物反应, 从而实现硝基苯的高效加氢. 其中Co@NC-1催化活性最高, 并在循环套用10次后, 仍维持较高的 催化活性, 同时对含其它取代基的硝基苯均表现很高的活性和选择性.
\end{abstract}

关键词: 钴颗粒; 氮掺杂碳; 硝基芳烃; 选择加氢; 氢活化; 多相催化

收稿日期: 2017-11-29. 接受日期: 2017-12-22. 出版日期: 2018-04-05.

*通讯联系人. 电话/传真: (022)27892340; 电子信箱: jj_zou@tju.edu.cn 基金来源：国家自然科学基金(U1462119); 天津市自然科学基金(16JCQNJC05200).

本文的电子版全文由Elsevier出版社在ScienceDirect上出版(http://www.sciencedirect.com/science/journal/18722067). 